\title{
Ontogenia da nodulação em duas cultivares de feijão-caupi
}

\author{
Ontogeny of nodulation in two cultivars of cowpea \\ Terezinha Ferreira Xavier ${ }^{\mathrm{I}}$ Ademir Sérgio Ferreira de Araújo ${ }^{\mathrm{II} *}$ \\ Valdinar Bezerra dos Santos ${ }^{\mathrm{I}}$ Francilene Leonel Campos ${ }^{\mathrm{II}}$
} \begin{abstract}
O objetivo deste trabalho foi avaliar a ontogenia
da nodulação em duas cultivares de feijão-caupi. O experimento RESUMO foi conduzido em casa de vegetação utilizando-se as cultivares "BRS-Guariba” e "BRS-Marataoã” cultivadas em sacos plásticos com $5 \mathrm{~kg}$ de areia. A adubação mineral, isenta de $\mathrm{N}$, foi realizada na véspera da semeadura e as sementes foram inoculadas com Bradyrhizobium sp, estirpe BR 2001. As avaliações foram realizadas aos 10, 20, 30, 40, 50, 60 e 70 dias após emergência das plantas, sendo determinados o número, a massa seca e o tamanho dos nódulos e a matéria seca da parte aérea. As cultivares apresentaram maior número de nódulos aos 30 e 50 dias após a emergência. A massa e o tamanho dos nódulos aumentaram durante o ciclo das cultivares. A matéria seca da parte aérea aumentou até o estádio de formação de vagens, diminuindo até o final do ciclo fenológico. As cultivares "BRS-Guariba” $e$ "BRSMarataoã" apresentam comportamento semelhante em relação à nodulação pela estirpe utilizada.
\end{abstract}

Palavras-chave: Leguminosas, fixação de $N_{2}$, Bradyrhizobium.

\section{ABSTRACT}

The aim of this paper was at evaluating the ontogeny of nodulation in two cultivars of cowpea. The experiment was carried out in a greenhouse and was used the cultivars BRS-Guariba and BRS-Marataoã cultivated in plastic pots with $5 \mathrm{~kg}$ of sand. The mineral fertilization, without $N$, was made before the sowing and the seeds were inoculated with Bradyrhizobium sp, strain BR 2001. The evaluations were made to the 10, 20,30,40,50, 60 and 70 days after plant emergence, being measured nodule number, dry mass and size and shoot dry mass. The cultivars showed higher nodule number to 30 and 50 days after plant emergence. Nodule dry mass and size increased significantly during the cycle of cultivars. Shoot dry mass increased to stage of formation of pods, decreasing until the end of the phenological cycle. BRS-Guariba and BRSMarataoã cultivars present similar behavior in relation to nodulation by used strain.

Key words: Legumes, $N_{2}$, fixation, Bradyrhizobium.

O feijão-caupi é uma leguminosa de importância econômica e social para a população rural da região Norte e Nordeste do Brasil. Entretanto, a cultura apresenta baixa produtividade média, e uma das causas é a baixa disponibilidade de nutrientes no solo, principalmente de $\mathrm{N}$. O conhecimento do processo de nodulação e, conseqüentemente, da fixação biológica do $\mathrm{N}_{2}$ (FBN) é uma das formas de aumentar a produtividade da cultura (FRANCO et al., 2002).

A FBN é reconhecidamente eficiente em feijão-caupi que, quando bem nodulado, pode dispensar outras fontes de $\mathrm{N}$ e atingir altos níveis de produtividade (RUMJANEK et al., 2005). Segundo esses autores, estimativas da contribuição da FBN no campo são, entretanto, bastante variáveis, tendo sido obtidos valores numa faixa de 40 a $90 \%$ do total de $\mathrm{N}$ acumulado pela cultura. Essa variabilidade pode ser atribuída a diferenças tanto do genótipo da planta, como do rizóbio, que podem influenciar os níveis de FBN.

\footnotetext{
ICurso de Agronomia, Universidade Estadual do Piauí (UESPI), Campus de Parnaíba, Parnaíba, PI, Brasil.

IIUniversidade Federal do Piauí (UFPI), Campus de Bom Jesus, BR 135, km 3, 64900-000, Bom Jesus, PI, Brasil. E-mail: asfaruaj@yahoo.com.br. Autor para correspondência.

IIIUPI, Campus Reis Veloso, Parnaíba, PI, Brasil.
} 
Dessa forma, o conhecimento do início da nodulação e, conseqüentemente, da FBN torna-se importante, pois, após a inoculação e o início da FBN, pode ocorrer deficiência de $\mathrm{N}$ devido à falta de sincronização entre o esgotamento das reservas de $\mathrm{N}$ dos cotilédones e o início da nodulação (HUNGRIA et al., 1994). Segundo VARGAS et al. (1982), o início da nodulação no feijão comum ocorre aos sete dias após a emergência e, na soja, ocorre na segunda semana após o plantio.

Além disso, para espécies de crescimento determinado, tais como a soja, a nodulação se intensifica até o florescimento, havendo manutenção na nodulação até formação das vagens, quando se inicia a senescência dos nódulos (HUNGRIA et al., 1994). Por outro lado, para espécies de crescimento indeterminado, tais como o feijão comum e o feijãocaupi, pode ocorrer um prolongamento na nodulação após a formação das vagens. O objetivo deste trabalho foi avaliar a ontogenia da nodulação em duas cultivares de feijão-caupi.

O experimento foi conduzido em casa de vegetação na Universidade Estadual do Piauí, Campus de Parnaíba, no período de 30 de junho a 10 de setembro de 2005. Foram utilizadas duas cultivares de feijão-caupi (“BRS-Guariba” e "BRS- Marataoã”), cultivadas em sacos plásticos com 5kg de areia. A adubação mineral, isenta de $\mathrm{N}$, foi realizada na véspera do plantio, conforme recomendação técnica para a cultura. Para a inoculação das sementes, foi utilizado inoculante turfoso (concentração de $10^{9}$ células $\mathrm{g}^{-1}$ ), o qual continha a estirpe de Bradyrhizobium sp (BR 2001). A dosagem utilizada foi de $500 \mathrm{~g}$ de inoculante para $50 \mathrm{~kg}$ de semente, e a inoculação foi realizada com o umedececimento prévio das sementes com uma solução açucarada (10 \% p v $\left.{ }^{-1}\right)$ na proporção de $6 \mathrm{~mL} \mathrm{~kg}^{-1}$ de semente (HUNGRIA et al., 2001). A semeadura foi realizada utilizando cinco sementes por saco e o desbaste foi realizado aos cinco dias após a emergência, deixando-se uma planta por saco. Os sacos foram irrigados diariamente, para manter a umidade do solo próxima à capacidade de campo.

As avaliações foram realizadas aos 10, 20, 30, 40, 50, 60 e 70 dias após emergência e corresponderam, respectivamente, aos estádios $\mathrm{V}_{3}, \mathrm{~V}_{6}$, $\mathrm{R}_{1}, \mathrm{R}_{2}, \mathrm{R}_{3}, \mathrm{R}_{4}$ e $\mathrm{R}_{5}$ (CAMPOS et al., 2000). Em cada avaliação, as plantas foram coletadas e as raízes foram separadas da parte aérea na base do caule. Os nódulos foram destacados, contados e colocados para secar em estufa a $65^{\circ} \mathrm{C}$ por 72 horas, sendo, em seguida, determinada a sua massa. A parte área, com exceção das vagens, foi colocada para secar em estufa a $65^{\circ} \mathrm{C}$ por 72 horas. O delineamento experimental foi inteiramente casualizado, em arranjo fatorial 2 × 7
(2 cultivares e 7 épocas de avaliação), em três repetições. Os dados foram submetidos a ANOVA e comparados entre si pelo teste de Duncan a 5\% de probabilidade.

A análise de variância mostrou que houve efeito significativo $(\mathrm{P}<0,05)$ para épocas de avaliação sobre todas as variáveis, enquanto que, tanto para cultivar, quanto para a interação cultivar x época, os efeitos foram não-significativos, indicando que houve diferenças significativas na nodulação e na produção de matéria seca durante o ciclo da cultura. Por outro lado, as duas cultivares apresentaram comportamentos iguais para essas variáveis, o que pode ser atribuído à semelhança morfo-fenológica entre elas, uma vez que foram selecionadas em programa de melhoramento (EMBRAPA, 2004 a,b), ou ainda ao fato de responderem de maneira semelhante, não havendo, portanto, interação cultivar x época. Resultados semelhantes foram observados por VASCONCELOS et al. (1976), estudando a nodulação em cultivares de Vigna simensis.

O número, a massa e o tamanho dos nódulos são indicadores usuais de nodulação (FERREIRA \& CASTRO, 1995). Na tabela 1, estão apresentados os dados da nodulação das cultivares durante o ciclo fenológico. Na primeira avaliação, aos 10 dias após a emergência, verificou-se a presença de nódulos nas raízes, indicando que a nodulação iniciou-se antes desse período. A nodulação aumentou significativamente durante o ciclo fenológico, com as duas cultivares apresentando maior número de nódulos aos 30 e 50 dias após a emergência, que corresponderam, respectivamente, aos estádios de início do florescimento $\left(\mathrm{R}_{1}\right)$ e formação das vagens $\left(\mathrm{R}_{3}\right)$. Nos estádios de início do florescimento e formação das vagens, a cultivar "BRS-Guariba" apresentou 120 e 97 nódulos e a cultivar "BRS-Marataõa” apresentou 155 e 148 nódulos, respectivamente, mas sem diferenças significativas entre si. Esses resultados apresentados pelo feijão-caupi em relação à nodulação foram semelhantes aos observados por VASCONCELOS et al. (1976) em feijão-de-corda, HUNGRIA \& NEVES (1986) em feijão comum e HUNGRIA et al. (1994) em soja.

Houve aumento significativo na massa e no tamanho dos nódulos (Tabela 1) durante o ciclo fenológico das cultivares, indicando que, uma vez formados, os nódulos aumentaram a sua massa e, conseqüentemente, a eficiência da fixação de N . Embora neste trabalho não tenha sido quantificada a fîxação de $\mathrm{N}_{2}$, esta observação é importante pois, de acordo com DOBEREINER (1966), há uma correlação positiva entre a massa nodular e a quantidade de $\mathrm{N}$ acumulado em leguminosas, e essa correlação positiva foi encontrada por WADISIRISUK \& WEAVER (1985) em feijão-caupi. 
Tabela 1 - Número, massa e tamanho de nódulos e massa da parte aérea seca em duas cultivares de feijão-caupi durante o ciclo fenológico.

\begin{tabular}{|c|c|c|c|c|c|c|c|}
\hline \multirow{2}{*}{ Cultivares } & \multicolumn{7}{|c|}{ Época de avaliação (dias após a emergência) } \\
\hline & 10 & 20 & 30 & 40 & 50 & 60 & 70 \\
\hline & \multicolumn{7}{|c|}{ Número de nódulos (n. planta $^{-1}$ ) } \\
\hline BRS-Guariba & $13 \mathrm{c}$ & $81 \mathrm{~b}$ & $120 \mathrm{a}$ & 62 bc & $97 \mathrm{ab}$ & $41 \mathrm{c}$ & $40 \mathrm{c}$ \\
\hline \multirow[t]{2}{*}{ BRS-Marataoã } & $8 \mathrm{~d}$ & $86 \mathrm{c}$ & 155 a & $132 \mathrm{~b}$ & $148 \mathrm{a}$ & $124 \mathrm{~b}$ & $101 \mathrm{c}$ \\
\hline & \multicolumn{7}{|c|}{ Massa dos nódulos secos (mg planta ${ }^{-1}$ ) } \\
\hline BRS-Guariba & $4,67 \mathrm{~g}$ & $59,9 \mathrm{f}$ & $429,2 \mathrm{~d}$ & $284,1 \mathrm{e}$ & $663,8 \mathrm{~b}$ & $508,1 \mathrm{c}$ & $792,1 \mathrm{a}$ \\
\hline \multirow[t]{2}{*}{ BRS-Marataoã } & $3,1 \mathrm{~g}$ & $38,4 \mathrm{f}$ & 354,5 e & $442,8 \mathrm{~d}$ & 638,8 c & 818,7 b & 980,1 a \\
\hline & \multicolumn{7}{|c|}{ Massa média de 1 nódulo (mg) } \\
\hline BRS-Guariba & 0,3 e & $0,7 \mathrm{e}$ & $3,5 \mathrm{~d}$ & $4,5 \mathrm{~d}$ & $6,8 \mathrm{c}$ & $12,3 \mathrm{~b}$ & 15,5 a \\
\hline \multirow[t]{2}{*}{ BRS-Marataoã } & $0,3 \mathrm{f}$ & $0,4 \mathrm{f}$ & $2,2 \mathrm{e}$ & $3,3 \mathrm{~d}$ & $4,3 \mathrm{c}$ & $6,6 \mathrm{~b}$ & $9,2 \mathrm{a}$ \\
\hline & \multicolumn{7}{|c|}{ Massa da parte aérea seca (g planta ${ }^{-1}$ ) } \\
\hline BRS-Guariba & $0,53 \mathrm{f}$ & $2,15 \mathrm{e}$ & $4,36 \mathrm{~d}$ & $7,53 \mathrm{c}$ & 20,23 a & $9,2 \mathrm{~b}$ & 7,1 c \\
\hline BRS-Marataoã & $0,37 \mathrm{e}$ & $1,88 \mathrm{~d}$ & $3,43 \mathrm{c}$ & $8,47 \mathrm{~b}$ & $16,7 \mathrm{a}$ & 15,3 a & $10,1 \mathrm{~b}$ \\
\hline
\end{tabular}

${ }^{(1)}$ Médias não seguidas pelas mesmas letras minúsculas na linha diferem entre si pelo teste de Duncan a 5\% de probabilidade de erro.

Isso sugere que plantas com maior número de nódulos fixam mais N, embora, de acordo com HANSEN et al. (1983), essa correlação não seja linear e, portanto, é necessário não só muitos nódulos, mas nódulos grandes, com maior eficiência relativa.

A matéria seca da parte aérea aumentou até o estádio de formação de vagens $\left(\mathrm{R}_{3}\right)$, diminuindo gradativamente até o final do ciclo fenológico (Tabela 1 ). Isso ocorreu porque, normalmente, as plantas acumulam biomassa até a fase de reprodução e, a partir dessa fase, inicia-se a senescência vegetal com conseqüente diminuição gradativa da biomassa (EPSTEIN \& BLOOM, 2006). O crescimento das cultivares ocorreu normalmente, sem aparecimento de sintomas de deficiência em N. Esse fato indica que a elevada nodulação apresentada pelas cultivares neste estudo proporcionou o crescimento satisfatório dos genótipos. Segundo HUNGRIA \& BOHRER (2000), há correlação positiva entre a massa dos nódulos e a matéria seca da parte aérea, sendo que esses autores observaram alta correlação entre a massa dos nódulos e a matéria seca da parte aérea em 152 cultivares de soja.

As cultivares “BRS-Guariba” e "BRSMarataoã” apresentam comportamento semelhante em relação à nodulação pela estirpe utilizada com aumento inicial no número de nódulos e diminuição gradativa até o final do ciclo fenológico das plantas.

\section{AGRADECIMENTOS}

Ao Conselho Nacional de Desenvolvimento Científico e Tecnológico (CNPq), pela concessão de bolsa de Iniciação Científica (PIBIC/CNPq/UESPI).

\section{REFERENCIAS}

CAMPOS, F.L. et al. Ciclo fenológico em caupi (Vigna unguiculata L. Walp): uma proposta de escala de desenvolvimento. Revista Científica Rural, v.5, p.110116, 2000.

DOBEREINER, J. Evaluation of nitrogen fixation in legumes by the regression of total plant nitrogen with nodule weight. Nature, v.210, p.850-852, 1966.

EMBRAPA... BRS-Marataõa: cultivar de feijão-caupi com grão sempre verde. Teresina: Embrapa Meio Norte, 2004a. $8 \mathrm{p}$.

EMBRAPA... BRS-Guariba nova cultivar de feijão-caupi para a região Meio Norte. Teresina: Embrapa Meio Norte, 2004b. 8p.

EPSTEIN, E.; BLOOM, A.J. Nutrição e crescimento. In: . (Eds). Nutrição mineral de plantas. Londrina: Planta, 2006. p.251-286.

FERREIRA, E.M.; CASTRO, I.V. Nodulation and growth of subterranean clover (Trifolium subterraneum L.) in soils previously treated with sewage sludge. Soil Biology and Biochemistry, v.27, p.1177-1183, 1995.

FRANCO, M.C. et al. Nodulação em cultivares de feijão dos conjuntos gênicos andino e meso-americano. Pesquisa Agropecuária Brasileira, v.37, p.1145-1150, 2002.

HANSEN, A.P. et al. Respiration and nitrogen fixation of hydroponically cultured Phaseolus vulgaris L. cv OAC Rico and supernodulant mutant I. Growth, mineral composition and effect of sink removal. Planta, v.189, p.538-545, 1983.

HUNGRIA, M. et al. Fixação biológica do nitrogênio em soja. In: ARAUJO, R.S.; HUNRIA, M. (Eds). Microrganismos de importância agrícola. Brasília: Embrapa-spi, 1994. p.9-90.

HUNGRIA, M. et al. Fixação biológica do nitrogênio na cultura da soja. Londrina: Embrapa Soja, 2001. 48p. 
HUNGRIA, M.; BOHRER, T.R.J. Variability of nodulation and dinitrogen fixation capacity among soybean cultivars. Biology and Fertility of Soils, v.31, p.45-52, 2000.

HUNGRIA, M.; NEVES, M.C.P. Ontogenia da fixação biológica do nitrogênio em Phaseolus vulgaris. Pesquisa Agropecuária Brasileira, v.21, p.715-730, 1986.

RUMJANEK, N.G. et al. Fixação biológica do nitrogênio. In: FREIRE FILHO, F.R. et al. (Eds). Feijão-Caupi; avanços tecnológicos. Brasília: EMBRAPA, 2005. p.281-335.
VARGAS, M.A.T. et al. Adubação nitrogenada, inoculação e épocas de calagem para a soja em um solo do cerrado. Pesquisa Agropecuária Brasileira, v.17, p.1127-1132, 1982.

VASCONCELOS, I. et al. Nodulação do feijão-de-corda, Vigna simensis (L) Savi ao longo do ciclo cultural da planta. Ciência Agronômica, v.6, p.11-15, 1976.

WADISIRISUK, P.; WEAVER, R.W. Importance of bacteroid number in nodules and effective nodule mass to dinitrogen fixation by cowpeas. Plant and Soil, v.87, p.223-231, 1985. 